\title{
Arduino ile Uzaktan Switch Konfigürasyonu Yönetimi Tasarımı
}

\author{
Funda AKAR*1, Fulya ASLAY ${ }^{1}$, Yaşar CEYLAN ${ }^{2}$ \\ ${ }^{1}$ Erzincan Binali Yıldırım Üniversitesi, Mühendislik Fakültesi, Bilgisayar Mühendisliği Bölümü, \\ Erzincan, Türkiye \\ ${ }^{2}$ Erzincan Binali Yıldırım Üniversitesi, Adalet Meslek Yüksekokulu, Erzincan, Türkiye
}

Geliş / Received: 11/05/2018, Kabul / Accepted: 15/11/2018

\begin{abstract}
$\ddot{O} z$
Günümüzde mikrodenetleyiciler çok fonksiyonlu ve düşük maliyetli olmalarından dolayı birçok uygulamada tercih edilmektedir. Bu çalışmada Erzincan Üniversitesi bünyesindeki ağ cihazlarının konfigürasyonu ve yedeklenmesi işlemlerinde klasik masaüstü ya da dizüstü bilgisayar ihtiyacı ve yetkili personel bulunma zorunluluğu yerine; zamandan, maliyetten ve personelden kazanç sağlayan ve Arduino kullanılarak tasarlanan "Erserial" isimli bir sistem geliştirilmiştir. Geliştirilen sistem ayrıca kablolama işlerinde planlamanın kolaylaştırılmasını sağlamakla birlikte saha personelinin de işe dahil edilmesine olanak tanıyarak, genel olarak çalışma şartlarının daha iyi, işlemlerin daha hızlı ve kolay yapılabilmesini sağlamıştır.
\end{abstract}

Anahtar Kelimeler: Arduino, A ̆g Cihazları Yönetimi, Uzaktan Konfigürasyon, Switch Konfigürasyonu

\section{Management Design of Remote Switch Configuration with Arduino}

\begin{abstract}
Nowadays micro-controllers are preferred in many applications because they are multifunctional and low cost. In this study, a system named "Erserial", that was designed by using Arduino and provides time and cost-saving benefits, has been developed instead of having the necessity of having a classical desktop or laptop computer and authorized personnel in the configuration and back-up of the network devices in Erzincan University. The developed system has also made working conditions better, the operations faster and easier in general as well as allowing field staff to be involved by making the planning easier in cabling work.
\end{abstract}

Keywords: Arduino, Network Devices Management, Remote Configuration, Switch Configuration

\section{Giriş}

Çalışmada Üniversitenin Bilgi İşlem Daire Başkanlığı tarafindan yürütülen ă̆ cihazları ile ilgili işlemler için kolaylık sağlayan bir sistem tasarımı gerçekleştirilmiş ve sisteme "Erserial" ismi verilmiştir. Çalışmanın sonraki bölümlerinde sistem bu isimle anılacaktır. Erserial sayesinde Üniversitenin şehir merkezindeki ve şehir merkezinden uzak olan Yerleşke içerisindeki sistem odalarında bulunan switchlerin konfigürasyon işlemleri uzaktan Arduino kullanılarak yönetilebilmektedir. Çalışmanın amac1; zaman, maliyet ve personelden kazanç elde ederek saha personelinin de işe dahil edilmesini sağlamaktır.
İçinde hazır olarak mikro denetleyici, girişçıkış pinleri, osilatör vb. elektronik bileşenleri barındıran fiziksel dünyayı algilayan ve kontrol edebilmek için kullanılabilen basit bir bilgisayar olarak nitelendirilen Arduino, bir G/Ç kartı ve Processing/Wiring dilinin bir uygulamasinı içeren geliştirme ortamından oluşan bir fiziksel programlama platformudur (www.arduino.cc). Arduino günümüzde basit ve erişilebilir kullanıcı deneyimi sayesinde binlerce farkl1 proje ve uygulamada kullanılmaktadır. Arduino yazılımı, yeni başlayanlar için kullanımı kolay olmakla birlikte gelişmiş kullanıcılar için de esnektir. Mac, Windows ve Linux'ta çalışır. Düşük maliyetli olmasından dolayı eğitim alanında 
bilimsel araçlar oluşturmak için, kimya ve fizik ilkelerini ispatlamak için veya programlama ve robotik konularına başlamak için kullanılır. Tasarımcılar ve mimarlar etkileşimli prototipler, müzisyenler ve sanatç1lar kurulumlar için ve yeni müzik aletleri ile deneme yapmak için kullanmaktadırlar (Banzi, 2011; Warren et al. 2011). Arduino kartları üzerinde Atmega firmasının 8 ve 32 bit mikrodenetleyicileri bulunur. Arduino kütüphaneleri ile mikrodenetleyiciler kolaylıkla programlanabilir. Analog ve dijital girişleri sayesinde analog ve dijital veriler işlenebilir. Sensörlerden gelen veriler kullanılabilir ve dış dünyaya çıktılar (ses, 1şık, hareket vs.) üretilebilir.

Arduino özellikle son yıllarda s1klıkla kullanılan maliyeti düşük bir üründür. Literatürde Arduino kullanılarak tasarlanan birçok sistem bulunmaktadır. Örneğin akıllı ev sistemlerinde kablosuz ağ üzerinden donanımların kontrolünde (Algoiare, 2014; Kusriyanto \& Putra, 2016), Arduino ve GSM şebekesinin SMS hizmeti kullanılarak akıllı enerji ölçümü ile faturalandırma işleminde (Rahman vd., 2015), ayrica nesnelerin internetinde nesneleri uzaktan yönetebilmek (Ferreira vd., 2013) gibi çeşitli amaçlarla kullanılmaktadır.

AL-Kadi vd. (2013) yaptıkları bir çalışmada, Arduino mikro denetleyicisini kullanarak basit bir Wi-Fi iletişim analizörü tasarlamışlardır. Tasarladıkları sistem Wi-Fi Shield ile etkileşime girerek Wi-Fi ağlarının sayısal sonuçlarını bir LCD monitörde görüntülemektedir.

Akkuş (2016), Nesnelerin İnterneti (Internet of Things - IoT) teknolojisi ile internet üzerinde Arduino kullanarak herhangi iki farklı yerel ağa bağlı, programlanabilir mikrodenetleyiciler arasında kriptolu veri haberleşmesi gerçekleştirmiştir. $\mathrm{Bu}$ çalışmada mikrodenetleyici mimarisine sahip Arduino platformu üzerinde WEP protokolünü kullanan bir şifreleme altyapısı tasarlanarak WAN içerisinde bulunan iki nokta arasinda kriptolu bir kanal oluşturularak güvenli bir haberleşme altyapısı kurulmuştur.

Sazak ve Albayrak (2017), Wi-Fi modülü Arduino ile programlayarak internete bağlanabilen bir kablosuz erişim noktasının bulunduğu herhangi bir noktadaki sıcaklık ve nem değerlerini toplayabilen, bu değerleri uzak bir sunucuya (ThingSpeak) aktarabilen, bilgileri sosyal bir medya sitesi Twitter üzerinden paylaşabilen ve kritik değerleri mobil cihazlara (Android) bildirim olarak gönderebilen bir sistem tasarlamışlardır.

$\mathrm{Bu}$ çalışmada Arduino kullanılarak genel olarak ağ cihazlarının konfigürasyonu, yedeklenmesi ve yapilmasi planlanan kablolama işlerinde planlamanın kolaylaştırılması amaçlanmaktadır. $\mathrm{Bu}$ şekilde zamandan, maliyetten ve personelden kazanç sağlanması hedeflenmiştir.

Literatür taramasında direkt ağ cihazlarının konfigürasyonu için Arduino ile yapılmış bir çalışmaya rastlanmamış olup, yapılan çalışmanın bu anlamda bilime katkı sağlayacağı düşünülmektedir.

\section{Materyal ve Metot}

Sistem tasarımında; Arduino Mega, TTL to Serial convertor, $16 \times 2$ LCD ekran, $4 \times 4$ klavye, Layout, Ultrasonik mesafe sensörü, bakır plaka, Header (Erkek - erkek 180 ve 90 derecelik, Dişi - erkek) kullanılmıştır. Burada TTL to Serial convertor, Arduinodan aldığı TTL veriyi seri RS232 formatına dönüştürüp hedef noktaya iletmektedir. Arduino ile seri port üzerinden standart olarak basit bir iletişim kurup haberleşme yapmak için 9600 bps hız kullanılmaktadır. Böylece Erserial ile işlem yapılacak cihazın haberleşmesi ve komutların cihaz üzerinde işlenmesi sağlanmaktadır. LCD ekran ile menüler ve girişlerin görüntülenmesi sağlanmaktadır. Menü seçim girişleri ise klavye ile yapılmaktadir. Sistem tasarımında kullanılan ultrasonik mesafe sensörü ile gönderilen ses sinyallerinin geri dönüş süresine göre mesafe ölçümü yapılmaktadır. Böylece kablolama işlemleri için toplam kablo boyu hesaplanabilmektedir. Sistemdeki tüm elemanların bağlantısı tek taraflı bakır plaka üzerine yapılmıştır. Bakır plaka ile Arduino ve sisteme ait diğer modüllerin iletişimi header ara elemanı ile sağlanmaktadır.

Geliştirilen sistemin iş akış uygulama adımları aşağıda açıklanmıştır:

Kullanıcının klavye aracılığıyla seçim yapması sağlanır

Kullanıcı seçim yaptıktan sonra hangi menüyü seçtiğinin kontrolü yapılır

Seçilen menü fonksiyonuna dallanma gerçekleştirilir 
$\checkmark$ Menü fonksiyonunda cihaz ayarı için gerekli parametre (İnternet Protokolü (IP) vb.) varsa girilmesi beklenir

$\checkmark$ Girilen parametre ile menüyle ilgili cihaza gönderilecek komutlar oluşturulur

$\checkmark$ Oluşturulan komutlar sırasıyla seri port üzerinden cihaza aktarılır

$\checkmark$ Aktarılan komutların cihaz üzerinde çalıştırılması sağlanır

$\checkmark$ Tüm komutlar çalıştırıldıktan sonra cihazın son halinin yedeği oluşturulur

$\checkmark$ Oluşturulan yedek, Basit Dosya Aktarımı Protokolü (TFTP) ile IP adresi, dosya ismi olacak şekilde lokalde TFTP sunucu olarak çalışmada geliştirilen Erserial isimli sistem üzerine aktarılır

$\checkmark$ Tüm işlemler tamamlandıktan sonra kullanıcının menüye yönlendirilmesi ile yeniden seçim yapabilmesi sağlanır.

Şekil 1' de sistemin ana akış diyagramı, Şekil 2' de alt menü akış diyagramı gösterilmiştir.

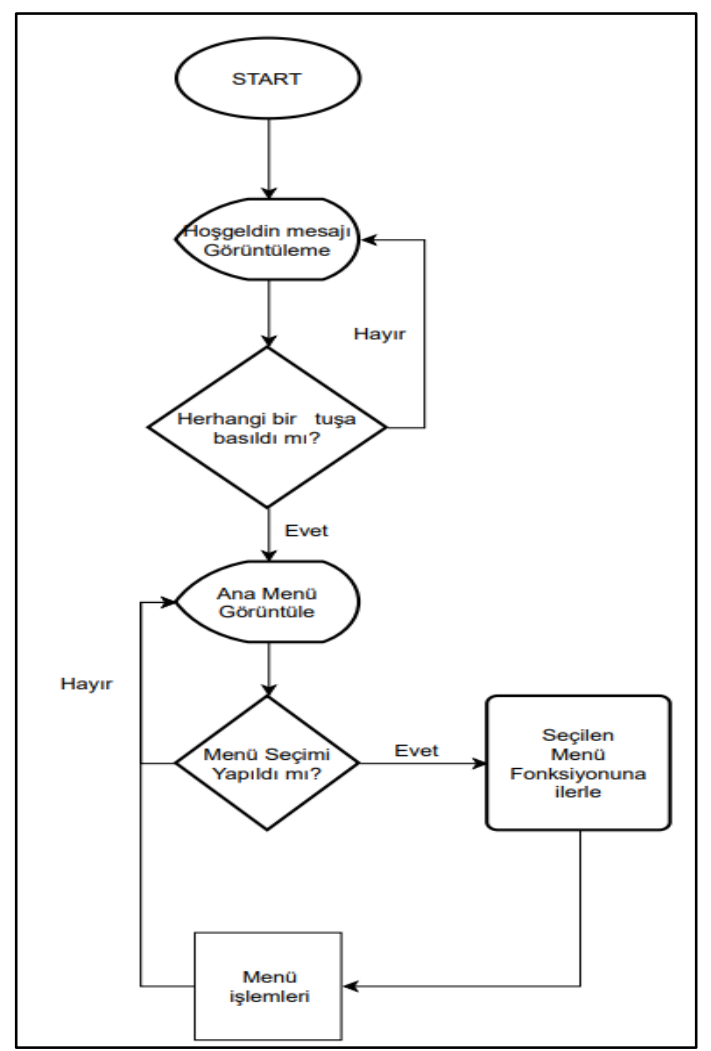

Şekil 1. Sistemin Akış Diyagramı.

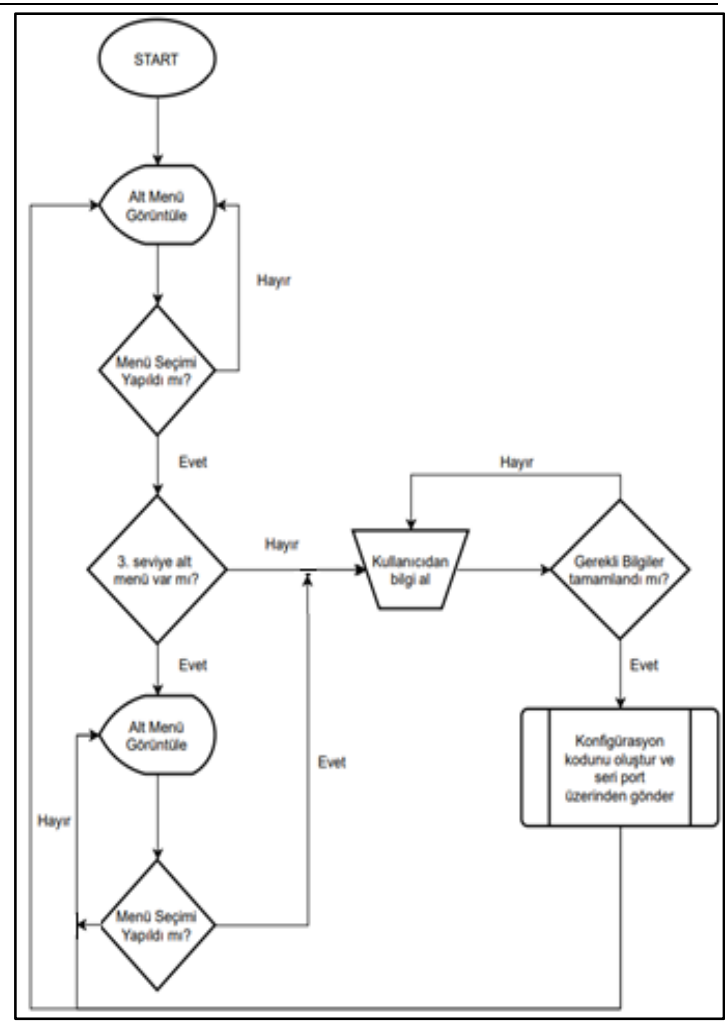

Şekil 2. Alt Menü Akış Diyagramı.

\section{Bulgular}

Geliştirilen Erserial isimli sisteme ait devre şeması Şekil 3' de verilmiştir.

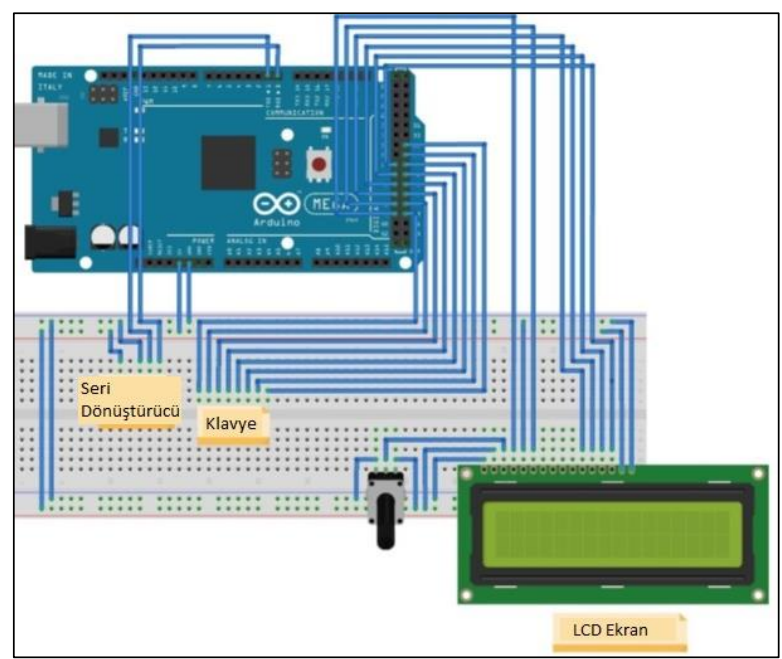

Şekil 3. Erserial Devre Şeması.

Sistem elemanlarının bakır plaka üzerine bağlanmış halinin üstten görünümü Şekil 4 (a)' da, alttan görünümü ise Şekil 4 (b)' de gösterilmiştir 


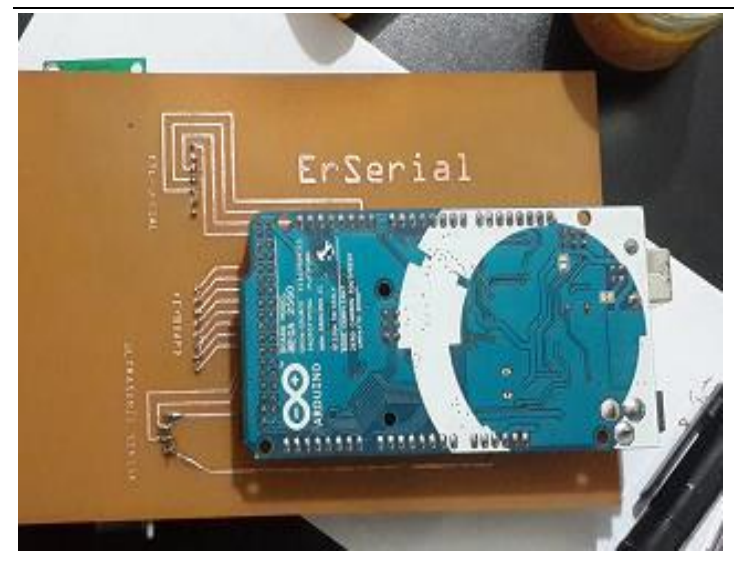

(a)

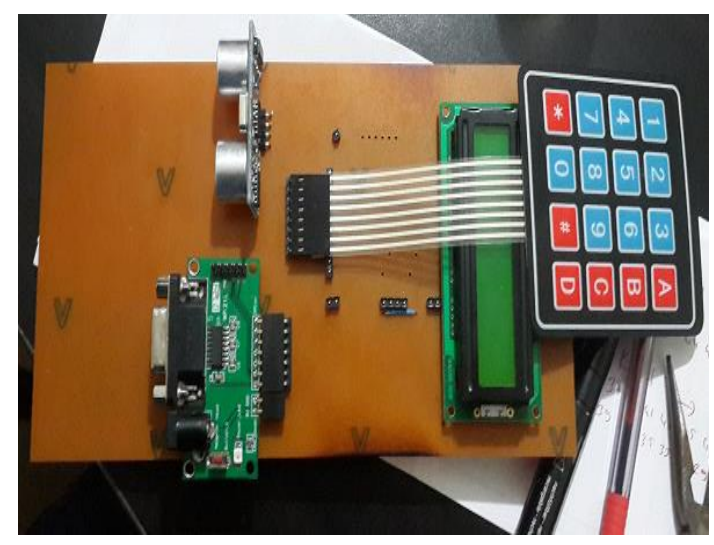

(b)

Şekil 4. Erserial Baskı Devre Üst ve Alt Görünümü.

Sistemin çalıșması sırasındaki örnek ekran görüntüleri Şekil 5' de gösterilmiştir.

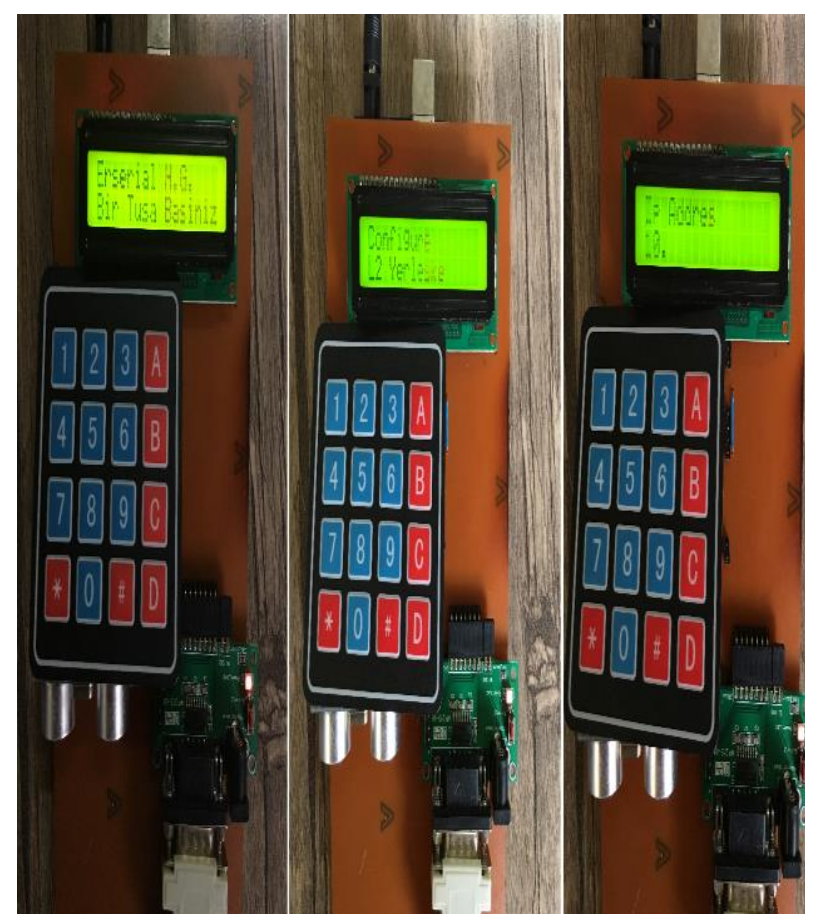

Şekil 5. Erserial Örnek Ekran Görüntüleri.

\section{Sonuç ve Öneriler}

$\mathrm{Bu}$ çalışmada genel olarak ağ cihazlarının konfigürasyonu ve yedeklenmesi işlemi Arduino kullanılarak geliştirilen ve Erserial ismi verilen sistem ile gerçekleştirilmiştir. Ayrıca aynı sistem ile kablolama işlerinin daha kolay planlanması da sağlanmıştır.

Önceki durum ile sistemin aktif edilerek hayata geçirilmesi sonrasında; zamandan, maliyetten ve personelden kazanç sağlanarak, saha personelinin işe dahil edilmesi ve çalışma kalitesinin artırılması sağlanmıştır.

Zamandan Kazanç: Normal olarak herhangi bir network cihazının konfigürasyonunun yapılabilmesi için öncelikle masaüstü ya da dizüstü bir bilgisayara ihtiyaç duyulmaktadır. Sonrasinda cihaz ve bilgisayar bağlantısının sağlanıp yetkili personelin gerekli ayarlamaları yapması gerekmektedir. Bu işlemler yapılırken kişi hata potansiyeli de göz önüne alındığında ayarların yapılıp kaydedilip yedeğinin alınması yaklaşık olarak $30 \mathrm{dk}$ sürmektedir. Fakat bu işlem geliştirilen Erserial ile bağlantı sağlanıp sadece 1 dakikada yapılabilmektedir. $\mathrm{Bu}$ da zamandan büyük oranda kazanç sağlandığını göstermektedir.

Maliyetten kazanç: Önceden konfigürasyon için masaüstü bilgisayara ya da seri porta sahip bir dizüstü bilgisayara ihtiyaç varken, geliştirilen Erserial' in kullanılması ile bu cihazlara ihtiyaç kalmamış ve maliyetten en az \% 90 oranında kazanç sağlanmıştır.

Personelden kazanç: Önceki sistemde network cihazlarının konfigurasyonu için en az bir yetkili personelin yerinde görevlendirilmesi gerekirken; Erserial ile uzaktan bağlantı kurulması mümkün olduğundan, istenilen her yerden sisteme müdahale edilebildiği için ayrıca bir personelin görevlendirilmesine gerek kalmamıştır.

Saha personelinin işe dahil edilmesi: Kurumsal olarak her bir birimdeki personelin ă̆ cihazlarının konfigüre edilmesi konusunda yetkin ve donanımlı olması mümkün olmamaktadır. Fakat geliştirilen Erserial sistemi sayesinde bu konuda uzman olmayan personelin de tek 
bir cihazla yönlendirilmesi ile işe dahil edilmesi sağlanmıştır. Bunun yanı sıra, ağ problemlerine müdahalede, kalifiye personelin gelmesi beklenmeksizin probleme anında müdahale edilmesiyle sorunların anlık olarak çözümlenmesi mümkün olmuştur.

Çalışma kalitesinin artırılması: Sistem odalarındaki olumsuz ve sağlıksız çalışma koşulları yerine; Erserial kullanılarak, cihaz ile kablo bağlantısı sağlandıktan sonra istenilen her yerden sisteme anında müdahale edilebilmesinden dolayı hem çalışma süresi kısaltılmış hem de daha sağlıklı ortamlarda çalışmaya olanak sağlandığından çalışma kalitesi yükseltilmiştir.

\section{Teşekkür}

$\mathrm{Bu}$ çalışma Erzincan Üniversitesi BAP Koordinatörlüğü tarafından FEN-A-2105140077 no'lu proje olarak desteklenmiştir.

\section{Kaynaklar}

Akkuş, S. 2016. Nesnelerin İnterneti Teknolojisinde Güvenli Veri İletişimi -Programlanabilir Fiziksel Platformlar Arasinda WEP Algoritması ile Kriptolu Veri Haberleşmesi Uygulaması. Marmara Fen Bilimleri Dergisi, 3, 100-111.

Algoiare, O.T. 2014. Design and Implementation of Intelligent Home Using Gsm Network. Çankaya Üniversitesi, Yayınlanmamış Yüksek Lisans Tezi. S. 12

AL-Kadi, T., AL-Tuwaijri, Z., AL-Omran, A. 2013. Arduino Wi-Fi network analyzer. Procedia Computer Science, 21, 522-529, ISSN 1877-0509, https://doi.org/10.1016/j.procs.2013.0 9.073.

Banzi, M. 2011. Getting Started with Arduino. 2nd Edition. O'Reilly, USA.

Ferreira, H. G., Canedo, E. , Sousa, R. 2013. IoT architecture to enable intercommunication through REST API and UPnP using IP, ZigBee and arduino View Document, Wireless and Mobile Computing, Networking and Communications (WiMob). IEEE 9th International Conference, 7-9 Ekim. 2013.

https://www.arduino.cc/en/Guide/Introductio n, Son erişim Tarihi: 05.01.2018.

Kusriyanto, M, Putra, B.D. 2016. Smart home using local area network (LAN) based arduino mega 2560, https://ieeexplore.ieee.org/document/ 7870866/authors?ctx=authors Son Erişim Tarihi: 05.01.2018

Rahman, Md. M., Jannat, N., Islam, M.O., Salakin, Md. S. 2015. Arduino and GSM based smart energy meter for advanced metering and billing system. Electrical Engineering and Information Communication Technology (ICEEICT), 2015 International Conference, 21-23 May 2015.

Sazak, T, Albayrak, Y. 2017. Nesnelerin İnterneti (IoT) Üzerine Ortam Verilerini Toplayan ve Uzaktan Takibini Sağlayan Bir Sistem Tasarımı, 19. Akademik Bilişim Konferans1-AB, 8-10 Şubat Aksaray Üniversitesi, Aksaray.

Warren, J.D., Adams, J., Molle, H. 2011. Arduino Robotics (Technology in Action), ISBN-13 (electronic): 978-14302-3184-4, Apress, USA. 